blood biochemical values were: urea $21.2 \mathrm{mmol} / \mathrm{l}$, creatinine $428 \mu \mathrm{mol} / \mathrm{l}$, sodium $143 \mathrm{mmol} / \mathrm{l}$, chloride $112 \mathrm{mmol} / \mathrm{l}$, potassium $7 \cdot 2 \mathrm{mmol} / \mathrm{l}$. Muscle cramps due to dehydration and hyperkalaemia were diagnosed and his diuretics and captopril were stopped. He was treated with an insulin-dextrose infusion and calcium resonium. Over the next two days his cramps improved considerably and his serum potassium concentration fell to $4.8 \mathrm{mmol} / \mathrm{l}$. He was restarted on frusemide $\mathbf{4 0}$ $\mathrm{mg} /$ day and 10 days later was ready for discharge with good control of his heart failure. Biochemical values then were: urea $14.8 \mathrm{mmol} / \mathrm{l}$, creatinine $311 \mu \mathrm{mol} / \mathrm{l}$, sodium $142 \mathrm{mmol} / \mathrm{l}$, chloride $105 \mathrm{mmol} / \mathrm{l}$, potassium $4.0 \mathrm{mmol} / \mathrm{l}$

This case highlights the potentially dangerous interaction between angiotensin converting enzyme inhibitors and potassium sparing diuretics and the resultant rise in serum potassium concentration. Administration of captopril to patients taking diuretics causes a rise in serum potassium concentration. ${ }^{1}$ This is associated with a fall in circulating aldosterone values $^{2}$ and reduced potassium loss from the distal tubule. Captopril and other angiotensin converting enzyme inhibitors block the production of angiotensin II, which is the main stimulant to aldosterone release. Concurrent administration of potassium sparing diuretics or potassium supplements with captopril has been associated with hyperkalaemia. ${ }^{23}$ This was probably the cause in our patient, with his mild chronic renal failure also contributing, as captopril causes a rise in serum potassium values in chronic renal failure. ${ }^{14}$ The large dose of potassium sparing diuretic was probably also important. Hyperkalaemia with angiotensin converting enzyme inhibitors and potassium sparing diuretics is well recognised, but with combined preparations of potassium sparing and losing diuretics this interaction may be overlooked. Further confusion may arise with Frusene or similarly named preparations as these could potentially be mistaken for plain frusemide. This interaction may be so serious $^{3}$ that practitioners should have a clear knowledge of patients' diuretic or other treatment when initiating treatment with angiotensin converting enzyme inhibitors, and this risk should be borne in mind.

1 Ferroni C, Raffaeli S, Botta G, Paciaroni E. Diuretic induced hypokalaemia in uncomplicated systemic hypertension: effec of captopril on blood pressure, plasma potassium and ventricular ectopic activity. Postgrad Med f 1986;62 (suppl 1):131

2 Textor SC, Bravo EL, Fouad FM, Tarazi RC. Hyperkalemia in

azotemic patients during angiotensin-converting enzyme inhibition and ald

3 Packer M, Lee WH. Provocation of hyper-and hypokalemic sudden death during treatment with and withdrawal of converting enzyme inhibition in severe chronic congestive heart failure. Am 7 Cardiol 1986;57:347-8.

4 Zanella MT, Mattei E, Braibe SA, Kater CE, Ajzen H. Inadequate aldosterone response to hyperkalaemia during angiotensin converting enzyme inhibition in chronic renal failure. Clin Pharmacol Ther 1985;38:613-7.

\section{Does captopril exacerbate psoriasis?}

Drs N W Hamlet, M KeEFe, and Rebecca E I KERR (Department of Dermatology, Stobhill General Hospital, Glasgow G21 3UW) write: The most commonly reported side effects of captopril have been rashes. ${ }^{1}$ These are most often pruritic, maculopapular, and limited to the upper half of the body but may resemble pityriasis rosea ${ }^{2}$ or take the form of an urticate erythema with eczematous features leading to erythroderma. ${ }^{3}$ We have recently seen a 40 year old woman with a 16 year history of psoriasis, which flared dramatically after she took captopril for hypertension. Her psóriasis had previously been a stable plaque type, affecting the scalp, knees, and elbows, with minimal lesions elsewhere, and had never been itchy. In April 1987 she started taking captopril 12.5 mg twice daily for hypertension. She was taking no other drugs. After two weeks she developed a pruritic, scaly eruption, which was typical of guttate psoriasis although unlike the usual plaque pattern of her disease. The distribution was mainly central, affecting the back, buttocks, and posterior thighs. There was no history of sore throat or other illness, and an antistreptolysin $\mathrm{O}$ titre was 160 Todd units $/ \mathrm{ml}$. Captopril was continued. Outpatient treatment was un- successful, but inpatient treatment with tar, dithranol, and ultraviolet light cleared the psoriasis in August, and she subsequently remained clear. We cannot be certain that captopril exacerbated her psoriasis, but the time course makes an association plausible. The mode of presentation was consistent with a primar psoriatic reaction and we think it unlikely that psoriasis developed as an isomorphic (Köbner) phenomenon after an ordinary drug rash. There was no need to withdraw the drug, but rashes during captopril therapy can be transient and do not necessarily requir cessation of therapy. The possible mechanism of exacerbation is obscure, but rashes from captopril are thought to result from an allergic reaction to the sulphydryl component ${ }^{4}$ or from cutaneous kinin potentiation due to angiotensin converting enzyme inhibition, ${ }^{5}$ although this has been disputed. ${ }^{6} \mathrm{We}$ are not aware of published reports of this association, but one of the manufacturers (E R Squibb and Sons Ltd) has received two reports. In one case there was thought to be no causal relation, but the second patient developed severe psoriasis after changing from atenolol to captopril and required admission to hospita and withdrawal of the drug. We have reported ou case to the Committee on the Safety of Medicines.

We thank Miss L Gilbert of the drug information unit, Stobhill General Hospital, for reviewing the literature.

Di Bianco R. Adverse reactions with angiotensin converting enzyme (ACE) inhibitors. Medical Toxicology 1986;1:122-41.

Wilson KK, Hammond JJ, Kirkendall WM. The captopri induced eruption. Arch Dermatol 1980;116:902-5.

Goodfield MJ, Millard LG. Severe cutaneous reactions to captopril. BrMed f 1985;290:1111.

Gavras I, Gavras H. Captopril and enalapril. Ann Intern Med 1983;98:556-7.

5 Edwards JR, Coulter DM, Beasley DMG, MacIntosh D. Capto pril: 4 years of post marketing surveillance of all patients New Zealand. Brf Clin Pharmacol 1987;23:529-36.

6 Navis GJ, De Jong PE, Kallenberg CGM, et al. Absence of cross-

\section{Psoriasis as a side effect of $\beta$ blockers}

Drs M KeEFe, N W Hamlet, and Rebecca E I KerR Department of Dermatology, Stobhill General Hospital, Glasgow G21 3UW) write: Dr Jaakko Savol and colleagues (12 September, p 637) described exacerbations of pre-existing psoriasis or the development of psoriasis in 10 patients receiving $\beta$ blockers for hypertension or angina pectoris. They commen that angiotensin converting enzyme inhibitors were substituted in the hypertensive patients. A high prevalence of high renin essential hypertension has been claimed in psoriasis, ${ }^{1}$ and this seems to be a good reason for using this class of drugs. In a recent study 10 psoriatic patients with hypertension were treated with captopril. Three patients, however, developed reversible heavy proteinuria, and the authors concluded that there should be careful monitoring of urinary protein concentrations when the drug is used in people with psoriasis. Three patients also found that previously resistant skin lesions improved. ${ }^{2}$ The reason for this is unclear, however, and the authors were careful not to make a causal inference. In contrast, we have reported on a patient whose psoriasis flared dramatically after taking captopril (see accompanying report). $\beta$ Blockers are widely used and have a good safety record. We suggest that doctors should carefully consider the advantages and disadvantages of other drugs before changing their prescribing habits because of coexisting psoriasis.

We thank E R Squibb and Sons Limited for information referred to in this letter.

1 Ena $\mathrm{P}$, Madeddu $\mathrm{P}$, Glorioso $\mathrm{N}$, et al. High prevalence of cardiovascular diseases and enhanced activity of the renin angiotensin system in psoriatic patients. Acta Cardiol 1985;40: 199-205.

2 Madeddu P, Ena P, Dessi Fulgheri P, et al. Captopril induced proteinuria in hypertensive psoriatic patients. Nephron 1986; 44:358-60.

\section{Toxic coma induced by anticholinergic eye drops}

Drs J Nadal, V De la Fuente, M Abadias, ToRrent, and F Jané (Hospital de St Pau, Avda S
Antoni M Claret 167, 08025 Barcelona, Spain) write: Anticholinergic eye drops are regularly used by ophthalmologists to obtain mydriasis and cycloplegia. The most widely used are those containing atropine or scopolamine. Depending on the intensity and duration of the desired pharmacological effects, one or two drops are instilled in the conjunctival sac. ${ }^{12}$ Many side effects including systemic reactions ${ }^{3}$ may occur as a result of absorption of the topical drug particularly in (We describe a serious adverse reaction, which to our knowledge has has not been reported.

A 6 year old boy, weighing $22 \mathrm{~kg}$, was brought to the emergency room with a decrease in consciousness. He showed coma with agitation, dilated pupils, dry skin and mouth, facial flushing, a blood pressure of 120/70 $\mathrm{mm} \mathrm{Hg}$, and a heart rate of 160 beats/min, which increased progressively, reaching 230 beats/min with multifocal ventricular extrasystoles. Meningismus was absent. During an ophthalmoscopic examination one hour earlier the patient had been given two drops in each eye of an ophthalmic solution containing $2 \%$ atropine sulphate, $0.5 \%$ scopolamine bromhidrate, and $4 \%$ phenylephrine hydrochloride; the amounts instilled were about $3 \mathrm{mg}, 0.75 \mathrm{mg}$, and $6 \mathrm{mg}$ respectively. Atropine intoxication was considered and $0.5 \mathrm{mg}$ of physostigmine salicylate was given in an intravenous infusion over five minutes and repeated five minutes later. Ten minutes later the tachycardia decreased to 115 beats/min with a progressive recovery rom peripherical manifestations, although cognitive functions did not recover until 16 hours later. After 48 hours the patient was discharged with a residual mydriasis.

Toxic psychosis and delirium have been reported after routine instillation of eye drops containing anticholinergic agents for refraction. ${ }^{5}$ Systemic absorption probably takes place via the nasolacrimal duct through the nasal mucosa or from swallowed atropine laden tears through the walls of the gastrointestinal tract. Atropine and scopolamine can produce both systemic effects, including confusional states, delirium, and toxic psychosis among other central nervous system manifestations, ${ }^{6}$ and peripheral postganglionic cholinergic effects. In certain sensitive subjects these effects may arise with therapeutic doses. ${ }^{7}$ Recently a toxic psychosis was reported in a 6 year old girl who received an overdose, confirmed by measurements of free scopolamine plasma values from a transdermal scopolamine patch. ${ }^{8}$

The appearance of coma after the administration of a single dose of eye drops together with the fact that these kinds of drugs are widely used for inducing mydriasis and cycloplegia, should alert ophthalmologists to the severe central toxicity of these compounds, even at normal doses and especially in children. Neither the manufacturer (Laboratorios Llorens) nor the Department of Clinical Pharmacology and Drug Surveillance has received reports of such a side effect. We recommend reducing the risk of side effects from ophthalmic application of atropine, for instance by compressing the internal angle of the eye to obstruct the lacrimal duct during instillation of the drops. ${ }^{9}$ In children less concentrated atropine solutions, or other compounds with a lower central toxicity such as cyclopentolate or tropicamide, should be used instead of atropine alone or with scopolamine.

Merli GJ, Weitz H, Martin JH, et al. Cardiac dysrhythmia associated with ophthalmic atropine. Arch Intern Med 1986; 146:45-7.

Weiner $\mathbf{N}$. Atropine, scopolamine and related antimuscarinic drugs. In: Goodman Gilman A, Goodman LS, Rall TW, Murad F, eds. The pharmacological basis of therapeutics. New York: MacMillan, 1985: 130-44

3 Vadot E, Piasentin D. Frequence des allergies aux collyres. Resultats d'une enquete prospective en milieu hospitalier. $\mathcal{J} F$ Ophtalmol 1986;9:41-3.

Gallasch G, Schutz R, Gotz ML, Kraus-Mackiw E. Atropinnebenwirkungen: pharmakologische, allergische, pseudoallergische oder toxische reaktionen? Klin Monatsbl Augenheilkd 1982;181:96-9.

Hamborg-Petersen B, Nielsen MM, Thordal C. Toxic effect of 483-5.

6 Birkhimer LJ, Jacobson PA, Olson J, Goyette DM. Ocular scopolamine induced psychosis. 7 Fam Pract 1984;18:466-9.

7 Tune LE, Holland A, Folstein F, Damlouji NF, Gardner TJ, Coyle T. Association of postoperative delirium with raised serum levels of anticholinergic drugs. Lancet 1981 ;ii:651-2.

8 Sennhauser FH, Schwarz HP. Toxic psychosis from transdermal scopolamine in a child. Lancet 1986;ii: 1033.

Baker JP, Farley JD. Toxic psychosis following atropine eyedrops. BrMed f 1958;ii:1390-2.

₹ . . 